\title{
Superelasticity of NiTi-Nb metallurgical bonding via nanoindentation observation
}

\author{
Liqiang Wang1,2, Cong Wang2,3, Weijie Lu1, Di Zhang1 \\ 1 State Key Laboratory of Metal Matrix Composites, Shanghai Jiao Tong University, \\ Shanghai 200240, China \\ 2 Department of Materials Science \& Engineering, Northwestern University, \\ Evanston, Illinois, 60208, USA \\ 3 School of Materials and Metallurgy Northeastern University Shenyang, \\ 110819,China \\ E-mail: wang_liqiang@sjtu.edu.cn luweijie@sjtu.edu.cn \\ Tel: +862134202641 Fax: +862134202641
}

\begin{abstract}
:
Sandwich architecture with cross-shape periodic cellular cores is synthesized via eutectic reaction between $\mathrm{NiTi}$ and $\mathrm{Nb}$ powder, such forming metallurgical bonding between NiTi wires near eutectic reaction temperature. Superelasticity is investigated systematically via nanoindentation tests. The Ti-rich phase is weaker in superelastic recovery comparing with that of Nb-rich phase, lamellar and rod-like $\mathrm{NiTi}-\mathrm{Nb}$ eutectic. Inconsistent $\mathrm{Nb}$ element distribution in the interface of eutectic area and NiTi wire enhances the martensitic transformation.
\end{abstract}

Keywords : titanium alloys; nanoindentation; interfaces; sintering; superelastic recovery

\section{Introduction}

Many approaches have been carried out to fabricate metal foams with open cell and stochastic structures [1-3].Owing to the uniform and open architecture as well as isotropic performance, 
cellular metals with truss-type inner structures have been studied for a long time [4]. According to the quasi-binary NiTi-Nb eutectic phase diagram, spontaneous contact melting appears once $\mathrm{Nb}$ comes in contact with NiTi at high temperature, such a quasi-binary liquid eutectic phase with a composition near $\mathrm{Ni}-36 \mathrm{Ti}-26 \mathrm{Nb}$ (at.\%) is formed when $\mathrm{NiTi}$ and $\mathrm{Nb}$ are in contact with each other [5-7]. Grummon et al used $\mathrm{Nb}$ foils to bond NiTi foils, by creating a NiTi-Nb phase, into open-cell NiTi honeycombs with shape-memory properties [5]. Wang et al reported that high ductility and hardness can be obtained in NiTi-Nb eutectic region [6]. Comparing with superelasticity in NiTi titanium alloys [8-9], few literatures can be found focus basically on NiTi-Nb eutectic. Superelasticity of NiTi-Nb brazed NiTi wires with cross-shape architecture has not been systematically studied yet. In this study, sandwich architecture with periodic cellular cores is synthesized via eutectic reaction between $\mathrm{NiTi}$ and $\mathrm{Nb}$ powder. Superelasticity is investigated systematically via nanoindentation tests. Microstructure in the eutectic bonding region for cross brazed NiTi-Nb is also discussed.

\section{Experimental}

NiTi wires with a nominal composition of 50.5 at.\% Ni were utilized for brazing. Pre-alloyed NiTi powders (44-63 $\mu \mathrm{m}, 48.6$ at. $\% \mathrm{Ni})$ and pure $\mathrm{Nb}$ powders $(99.8 \%$ purity, $1-5 \mu \mathrm{m})$ were used. We design the weight ratio of pre-alloyed NiTi and $\mathrm{Nb}$ powders as 2.3 and sinter the specimen at $1165^{\circ} \mathrm{C}$ for 4 minutes in a high vacuum ( $10^{-5}$ torr) furnace. Figure 1(a) shows an example of sandwich framework with periodic cellular cores. In order to obtain this accurate structure, we prepare the cross-shaped bonded NiTi wires with $\mathrm{NiTi} / \mathrm{Nb}$ slurry added at each node, as exactly indicated in Fig.1(b). Nanoindentation tests were carried out at room temperature using a nanoindenter with a Berkovich tip, performed with the continuous load up to a maximum value of $50 \mathrm{mN}$ at a loading rate of $1.0 \mathrm{mN} / \mathrm{s}$. A $30 \mathrm{~s}$ dwelling time was applied at the maximum load of about $50 \mathrm{mN}$ followed by unloading at a 
unloading rate of $1.0 \mathrm{mN} / \mathrm{s}$. Scanning electron microscope (SEM) and energy-dispersive spectroscopy (EDS) observations were carried out using a Hitachi SU8030 microscope at $15 \mathrm{kV}$.

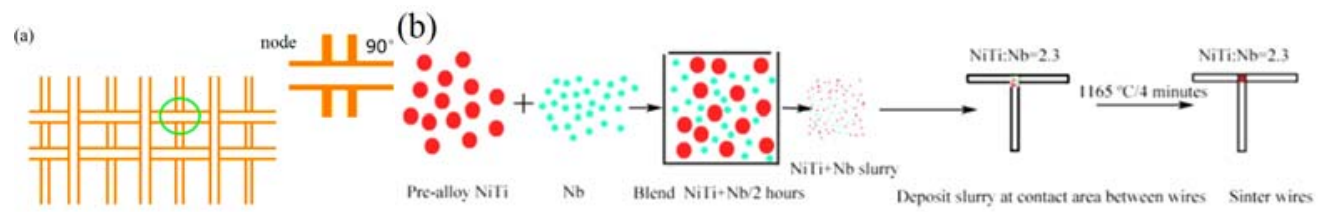

Fig.1 Schematic illustration of sample preparation: (a) Example of sandwich framework with periodic cellular cores; (b) Cross-shaped bonded NiTi wires with $\mathrm{NiTi} / \mathrm{Nb}$ slurry added at each node.

\section{Results and discussion}

We prepare two perpendicular wires to produce $\mathrm{NiTi} / \mathrm{Nb}$ eutectic at $1165^{\circ} \mathrm{C}$ (near the eutectic temperature in the $\mathrm{NiTi}-\mathrm{Nb}$ quasi-binary phase diagram [6]). Figure 2 shows the optical microstructure of as-polished surface of the brazed region, demonstrating an adequate metallurgical bonding in situ reaction processing, as exactly shown in enlarged micrograph of eutectic region in Fig.2(a). In region A (Fig.2(a)), martensite colonies appear at the interface of eutectic reaction (Fig. 2 (b)). The chemical composition for four different position $(1,2,3,4)$ in figure 2(b) were determined by EDS as follows: (1) 7.98Ti-7.65Ni-84.37Nb (wt.\%) (Nb-rich phase), (2) 42.76Ti-33.65Ni-23.59Nb (Ti-rich particle), (3) 36.24Ti-51.37Ni-12.39Nb (proeutectic phase), (4) 43.64Ti-56.36Ni (NiTi matrix). It can also be determined that much more martensite transformation was obtained at the interface between NiTi and eutectic region. In region $\mathrm{B}$ (Fig.2(a)), a continuous change of $\mathrm{Nb}$ content from the reaction area to NiTi matrix is shown in figures 2(d) and (e), as measured by EDS in the marked region. $\mathrm{Nb}$ concentration is higher in the eutectic area (position 1), especially in the Nb-rich phase, and drops to zero in the NiTi wires (position 4), indicating that solid-state diffusion of $\mathrm{Nb}$ into the wires is very limited during the 4 minutes at $1165^{\circ} \mathrm{C}$. 

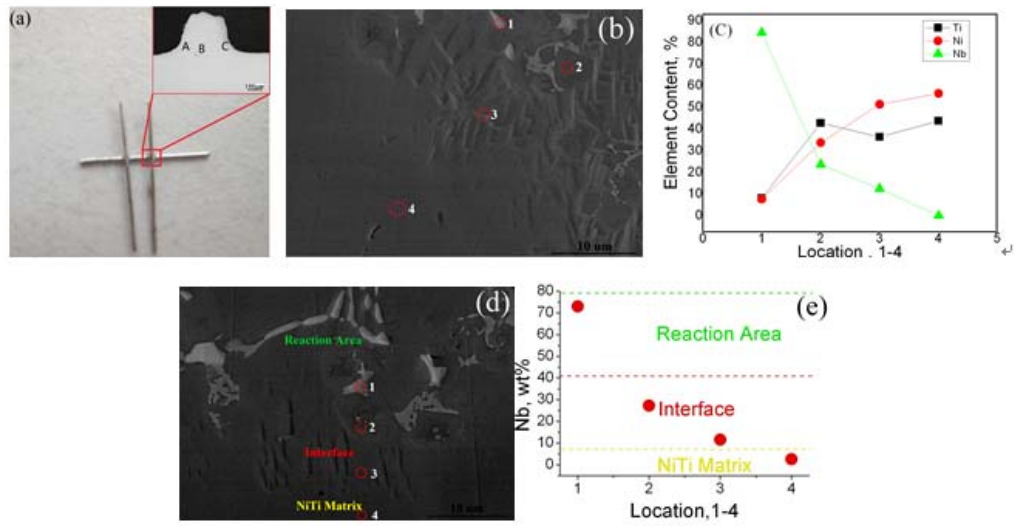

(e)

Fig 2 Micrographs of polished surface of the brazed region for cross-shape wires: (a) Sintered specimen and enlarged micrograph of eutectic region; (b) micrograph of reaction interface between NiTi wire and eutectic region, as marked by A in (a) ; (c) EDS analysis of each phase composition in (b); (d) micrograph of reaction interface between NiTi wire and eutectic region, as marked by B in (a); (e) change of $\mathrm{Nb}$ content in (d).

Figure 3 shows the images of nanoindents on the bonded area. The proeutectic phase (P), eutectic region (E), and Nb-rich phase (N') are also visible (Fig.3(a)). Figure 3(b) shows the load-displacement curves obtained from the eutectic region (Fig.3(a)). Clear difference of the load-displacement curves for the nine indents in the eutectic region can be observed. The curves seem the same in the NiTi matrix region (Fig.3(c)). Complete unloading does not result in a full shape recovery as one might expect for a superelastic feature. Both the maximum depth and residual depth of indentation varies from each other due to the different indented locations (Fig.3(b)). For indents 1, 4, 7, and 9, located around the interface between eutectic and $\mathrm{NiTi}(\mathrm{Nb})$ proeutectic phase, the maximum depths are greater than $900 \mathrm{~nm}$.

The relationships between the maximum indents depth at maximum load $\left(h_{\max }\right)$, residual depth during unloading $\left(h_{\mathrm{r}}\right)$, recovery ratio $\left(\eta_{\mathrm{d}}\right)$ and indents are shown in figures 3(d) and (e). As seen from Fig.3(d), superelastic recovery occurs and significant difference for those nine indenters is observed. 
For indents 3, 6, and 8 in the eutectic region, the values of $\eta_{\mathrm{d}}$ are around $49 \%$, and the values of others are relatively small ranging from $42 \%$ to $46 \%$. However, comparing with the superelasticity in the bonded area, more strain recovery (ranging from $50 \%$ to $52 \%$ ) is apparent after complete unloading for NiTi wire as indicated in figure 3(e).

For the indent $1,4,7$, and 9 , the depth is lower than that of the remanent indents. During unloading, the recovery curves associated with the stress-induced martensite transformation vary from each other. As shown in Ref. [10], martensite transformation is switched in which the slope of $\mathrm{P}(\mathrm{h})$ curve in the early stages of loading is not steep. Comparing with the eutectic region, a higher value of recovery ratio $(50-52 \%)$ can be observed in NiTi matrix. It is concluded that much more phase transformation from stress-induced martensite to parent occurs which is caused by elastic strain energy stored around the martensite plates and matrix. While similar recovery ratio values to NiTi around $49 \%$ are obtained for the indents 3, 6, 8, and 9 (Fig. 3(e)), which distribute in the interface between eutectic phase and $\mathrm{NiTi}(\mathrm{Nb})$ proeutectic phase, where martensite transformation is also induced easily.
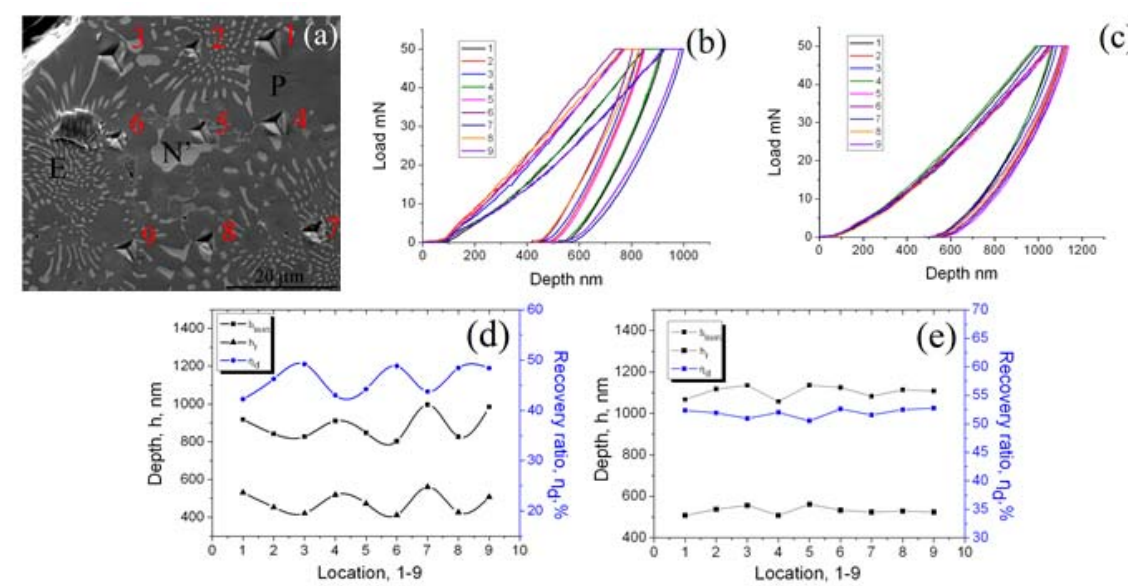

Fig.3 Nanoindents on polished surface sintered at $1165^{\circ} \mathrm{C}$ for 4 minutes: (a) SEM micrograph of region C in Fig.2(a); (b) load-displacement curves obtained from the nine indents in eutectic region (numbers correspond to indents shown in Fig. 3(a)); (c) load-displacement curves of NiTi wire; (d) 
recovery ratio for 9 indents in eutectic region, (e) recovery ratio for a NiTi wire.

The Hertzian elastic contact solution of nanoindentation tests can be calculated by [11]:

$$
\mathrm{P}=4 / 3\left(\mathrm{E}_{\mathrm{r}} \mathrm{R}_{\mathrm{i}}^{1 / 2} \mathrm{~h}^{3 / 2}\right)
$$

where $\mathrm{P}$ is the applied load, $\mathrm{E}_{\mathrm{r}}$ is the effective indentation modulus, $\mathrm{R}_{\mathrm{i}}$ is the radius of the indenter tip, which was determined as $1 \mathrm{um}$ in this experiment, $\mathrm{h}$ is the indentation depth. Young's modulus and Poisson's ratio for the indenter and the tested specimen are taken as $1140 \mathrm{GPa}, 0.07$ [12] and $73 \mathrm{GPa}$, 0.3 [10], respectively. Figure 4 shows nanoindentation results obtained with Hertzian solution and magnified indentation curve at the position of the pop-ins for four different indents, including indent 1 in NiTi matrix, indent 1, 3, and 8 in eutectic, respectively. Hertzian elastic contact solution is presented as a red dash dot line (Fig.4). First pop-in is considered as the result of dislocation nucleation [13-14]. First pop-in occurs below $1.5 \mathrm{mN}$ for indent 1 in NiTi matrix, while first pop-in events in other indents in eutectic region appear above $4 \mathrm{mN}$, and the largest value arrives around $8 \mathrm{mN}$ for indent 8 in eutectic. The following pop-ins may be caused by martensitic transformation, as discussed by Ahn et al. [15]. Comparing with the three indents in eutectic, distinct pop-ins are detected during loading procedure, especially for indent 3 and indent 8 , showing that martensite transformation occurs during the indentation. Furthermore, as shown in figure 4(d) about the superelastic recovery for the indents 1,3 , and 8, respectively, higher values are obtained for indents 3 and 8 , which also confirms the fact that much martensite transformation takes place in indents 3 and 8.
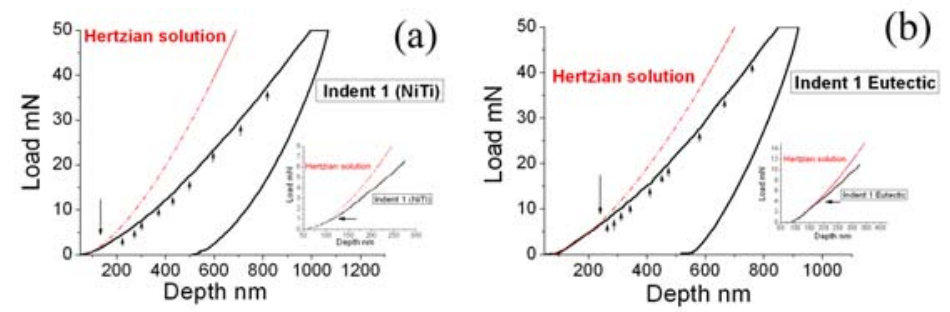

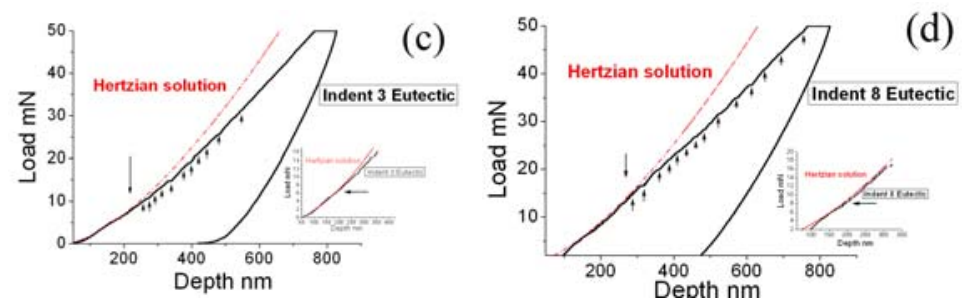

Fig.4 Nanoindentation experiments conducted with Berkovich indent with Hertzian solution including an enlarged part of the indentation curve: (a) indent 1 in NiTi matrix, (b) indent 1 in eutectic, (c) indent 3 in eutectic, (d) indent 8 in eutectic. Arrows indicate the position of the pop-ins

\section{Conclusions}

Comparing with the superelasticity in bonding area, more strain recovery is observed for NiTi wire and the values range from $50 \%$ to $52 \%$. Ti-rich phase is weaker in superelastic recovery comparing with $\mathrm{Nb}$-rich phase, lamellar and rod-like NiTi-Nb eutectic. Lower values of recovery ratio are obtained in different phase in eutectic region comparing with the value of NiTi matrix. Inconsistent $\mathrm{Nb}$ element distribution in the interface of eutectic area and NiTi wire enhances the martensitic transformation, where martensite transformation is also induced easily.

\section{Acknowledgements}

This research was supported by DARPA under the grant W91CRB1010004 and the National Science Foundation under grant No. 51302168 of China. Shanghai Pujiang Program:15PJD017. Useful discussions with David C. Dunand (Northwestern U.) are acknowledged. The authors gratefully acknowledge experimental hardness measurements by Dr. Lechun Xie from Shanghai Jiao Tong University and tensile tests by Eddie Kao of Northwestern University.

\section{References:}

[1] J.Banhart, Prog.Mater.Sci. 46(2001)559-632.

[2] A. R. Nagel, C. Uslu, K. J. Lee, J. K. Cochran, T. H. Sanders, Mat. Res. Soc. Symp. Proc. 
372(1995)155-163.

[3] D.J. Sypeck, P.A. Parrish, H.N.G. Wadley, Mat. Res. Soc. Symp. Proc. 521(1998)205-210.

[4] H.N.G. Wadley, Philos. Trans. R. Soc. A 364(2006)31-68.

[5] D.S. Grummon, J.A. Shaw, J. Foltz, Mater. Sci. Eng. A. 438-440(2006) 1113-1118.

[6] L.Q. Wang, C. Wang, D. C. Dunand, Metall. Mater. Trans.A 46(2015)1433-1436.

[7] D.S. Grummon, J.A. Shaw, A. Gremillet, J. Appl. Phys. Lett. 82 (2003) 2727-2729.

[8] J.I. Kim, Y.N. Liu, S. Miyazaki, Acta Mater. 52 (2004) 487-499.

[9] S. Kustov, D. Salas, E. Cesari, R. Santamarta, J. Van Humbeeck, Acta Mater. 60 (2012) 2578-2592.

[10] J. Pfetzing-Micklich, C. Somsen, A. Dlouhy, C. Begau, A. Hartmaier, M. Wagner, G. Eggeler, Acta Mater. 61 (2013) 602-616.

[11] K.L. Johnson, Contact Mechanics, Cambridge, 1985.

[12] S. Shim, H. Bei, E.P. George, G.M. Pharr, Scr. Mater. 59 (2008) 1095-1098.

[13] T.H. Ahn, S.B. Lee, K.T. Park, K. H. Oh, H.N. Han, Mater. Sci. Eng. A.598 (2014) 56-61.

[14] B.B. He, M.X. Huang, Z.Y. Liang, A.H.W. Ngan, H.W. Luo, J. Shi, W.Q. Cao, H. Dong, Scr. Mater. 69 (2013) 215-218.

[15] T.H. Ahn, C.S. Oh, D.H. Kim, K.H. Oh, H. Bei, E.P. George, H.N. Han, Scr. Mater. 63 (2010) 540-543. 
(a)

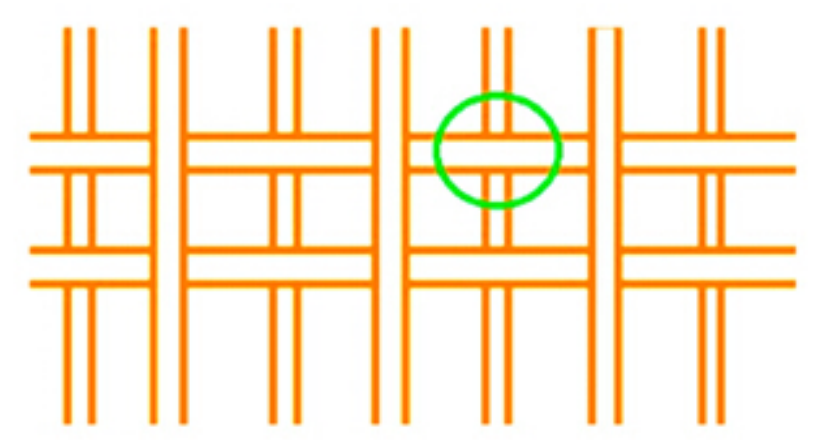

(b)

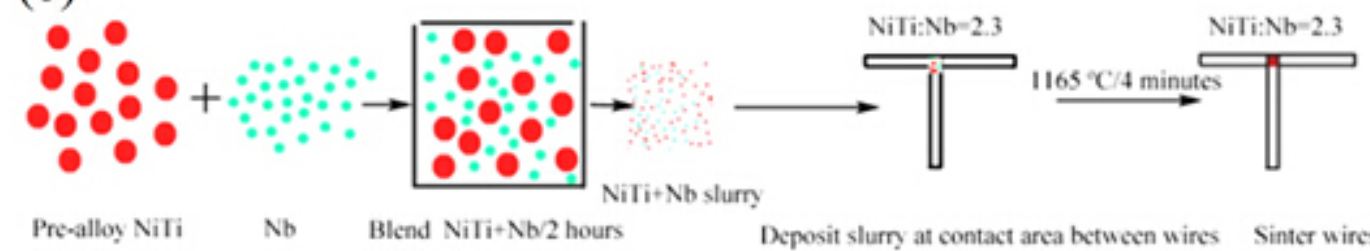

(a)Example of sandwich framework with periodic cellular cores; (b) Cross-shaped bonded $\mathrm{NiTi}$ wires with $\mathrm{NiTi} / \mathrm{Nb}$ slurry added at each node

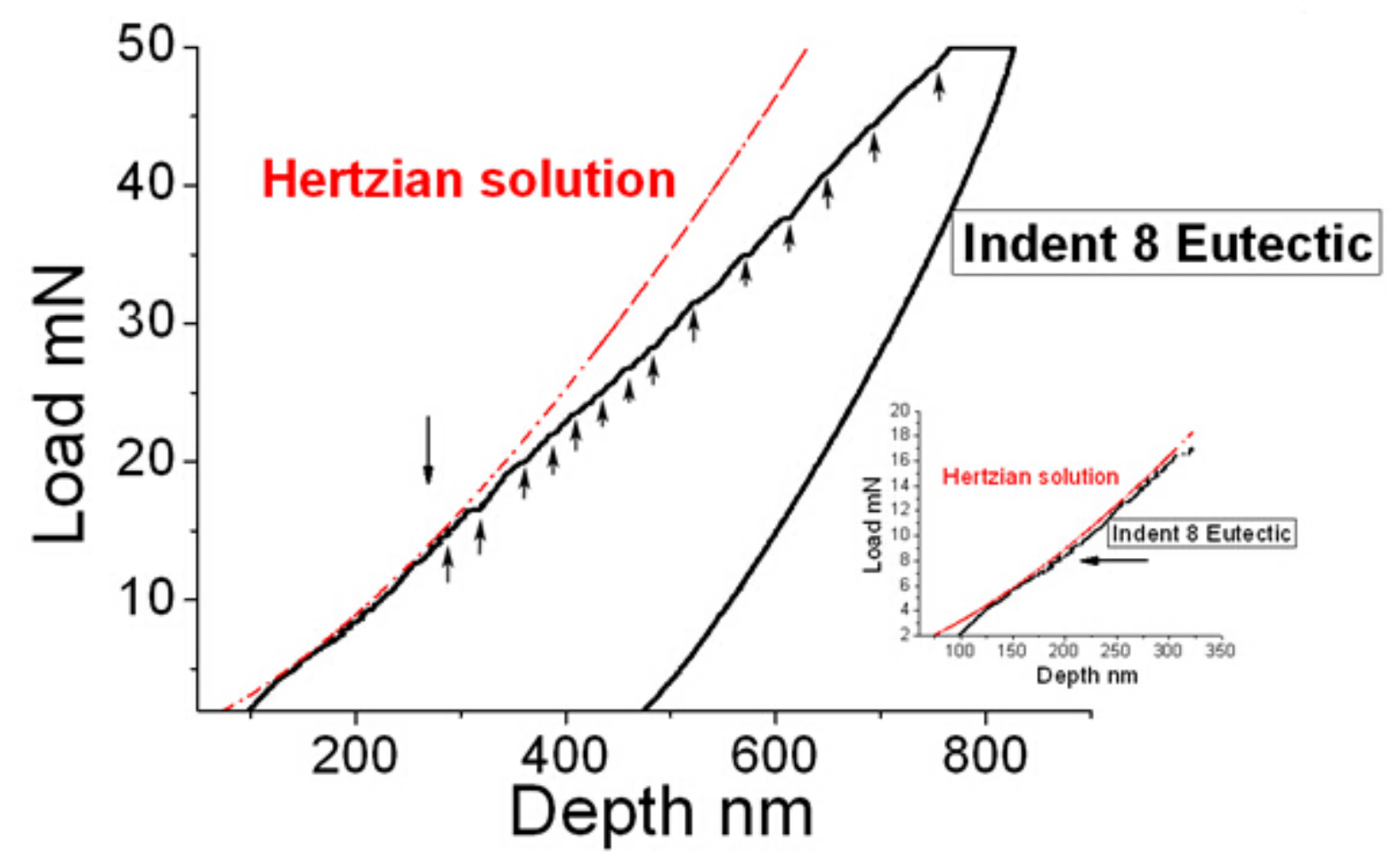

Nanoindentation experiments conducted with Berkovich indent 